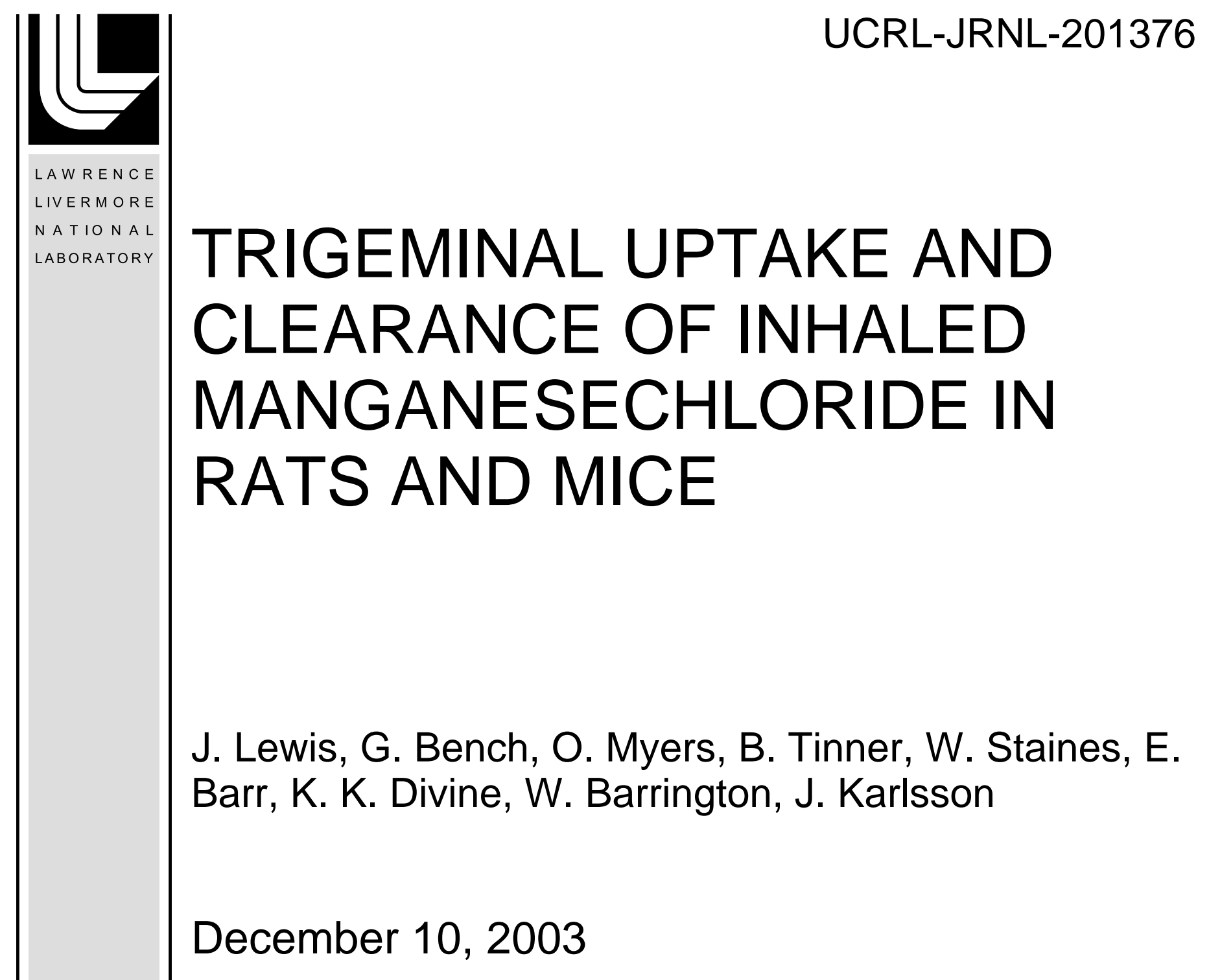

Neurotoxicology 
This document was prepared as an account of work sponsored by an agency of the United States Government. Neither the United States Government nor the University of California nor any of their employees, makes any warranty, express or implied, or assumes any legal liability or responsibility for the accuracy, completeness, or usefulness of any information, apparatus, product, or process disclosed, or represents that its use would not infringe privately owned rights. Reference herein to any specific commercial product, process, or service by trade name, trademark, manufacturer, or otherwise, does not necessarily constitute or imply its endorsement, recommendation, or favoring by the United States Government or the University of California. The views and opinions of authors expressed herein do not necessarily state or reflect those of the United States Government or the University of California, and shall not be used for advertising or product endorsement purposes. 


\section{TRIGEMINAL UPTAKE AND CLEARANCE OF INHALED MANGANESE CHLORIDE IN RATS AND MICE}

J. Lewis ${ }^{1}$, G. Bench ${ }^{2}$, O. Myers ${ }^{1}$, B. Tinner ${ }^{3}$, W. Staines ${ }^{3}$, E. Barr ${ }^{4}$, K.K. Divine ${ }^{4}$, W. Barrington $^{1}$, J. Karlsson ${ }^{1}$.

${ }^{1}$ Community Environmental Health Program, University of New Mexico, Albuquerque, NM, USA; ${ }^{2}$ Center for Accelerator Mass Spectrometry, Lawrence Livermore National Laboratory, Livermore, CA, USA; ${ }^{3}$ University of Ottawa, Ottawa, ON, Canada;

${ }^{4}$ Lovelace Respiratory Research Institute, Albuquerque, NM, USA; ${ }^{4}$ Lovelace Respiratory Research Institute, Albuquerque, NM, USA;

Corresponding author: Johnnye Lewis, Ph.D., DABT

Director, Community Environmental Health Program

Department of Internal Medicine, University of New Mexico Health Sciences Center MSC 10 5550, 1 University of New Mexico

Albuquerque, NM 87131-0001

Phone: +1-505-272-4853, Fax: +1-505-272-4186

Email: jlewis@cybermesa.com 


\section{ABSTRACT}

Inhaled manganese $(\mathrm{Mn})$ can enter the olfactory bulbs via the olfactory epithelium, and can then be further transported trans-synaptically to deeper brain structures. In addition to olfactory neurons, the nasal cavity is innervated by the maxillary division of the trigeminal nerve that projects to the spinal trigeminal nucleus. Direct uptake and transport of inhaled metal particles in the trigeminal system has not been investigated previously. We studied the uptake, deposition, and clearance of soluble Mn in the trigeminal system following nose-only inhalation of environmentally relevant concentrations. Rats and mice were exposed for 10 days (6 hours/day, 5 days/week) to air or $\mathrm{MnCl}_{2}$ aerosols containing $2.3 \pm 1.3 \mathrm{mg} \mathrm{Mn} / \mathrm{m}^{3}$ with mass median aerodynamic diameter (MMAD) of $3.1 \pm 1.4 \mu \mathrm{m}$ for rats and $2.0 \pm 0.09 \mathrm{mg} \mathrm{Mn} / \mathrm{m}^{3} \mathrm{MnCl}_{2}$ with $\mathrm{MMAD}$ of $1.98 \pm 0.12 \mu \mathrm{m}$ for mice. $\mathrm{Mn}$ concentrations in the trigeminal ganglia and spinal trigeminal nucleus were measured 2 hours (0 day), 7, 14, or 30 days post-exposure using Proton Induced X-ray Emission (PIXE). Manganese-exposed rats and mice showed statistically elevated levels of Mn in trigeminal ganglia 0,7 and 14 days after the 10 day exposure period when compared to control animals. The Mn concentration gradually decreased over time with a clearance rate $\left(t_{1 / 2}\right)$ of 7-8 days. Rats and mice were similar in both average accumulated Mn levels in trigeminal ganglia and in rates of clearance. We also found a small but significant elevation of $\mathrm{Mn}$ in the spinal trigeminal nucleus of mice 7 days post-exposure and in rats 0 and 7 days post-exposure. Our data demonstrate that the trigeminal nerve can serve as a pathway for entry of inhaled Mn to the brain in rodents following nose-only exposure and 
raise the question of whether entry of toxicants via this pathway may contribute to development of neurodegenerative diseases.

Key words: nose-only inhalation, PIXE, neurodegenerative disease, neurotoxicity, manganism, metal transport 


\section{INTRODUCTION}

Inhaled manganese $(\mathrm{Mn})$ and other toxicants can be directly transported into the central nervous system (CNS) via the olfactory nerve (Divine et al., 1999; Tjälve and Henriksson, 1999, Gianustos et al., 1997, Henriksson et al., 1997, Brenneman et al., 2000, Normandin et al., 2002). Transsynaptic transport of these toxicants has also been

demonstrated (Henriksson et al., 1997; Gianutsos et al., 1997; Tjälve et al., 1996) raising the possibility that this mechanism may contribute to the etiology of slow-developing neurodegeneration.

In occupational exposures, inhalation of Mn has been associated with development of a Parkinson's like syndrome (manganism) and the uptake and transport of inhaled Mn via the olfactory nerves has been postulated as the underlying mechanism in the etiology of this syndrome (Henriksson et al., 1999). The potential neurotoxicity of inhaled Mn has raised public health concerns over the recent addition of methylcyclopentadienyl manganese tricarbonyl (MMT) to both gasoline and diesel fuel mixtures (Kaiser, 2003). Combustion of MMT in fuel mixtures produces particulate matter primarily containing $\mathrm{Mn}$ phosphate with a mass median aerodynamic diameter (MMAD) less than 2.5 micron (PM 2.5) (Ressler et al., 1999). Particles of this size or smaller not only are readily respired and are associated with respiratory health problems, but also deposit on the olfactory epithelium, raising the potential for direct CNS transport (Cheng et al., 1989). Although environmental concentrations of Mn may not present health concerns via deposition in the CNS resulting from systemic distribution, the potential for direct non-systemic deposition of inhaled materials via the olfactory 
pathway to result in a greater localized CNS deposition than systemic delivery has been demonstrated (Divine et al., 1999; Tjälve and Henriksson, 1999). Recent studies show that the regional CNS localization of Mn after inhalation exposure depends on the solubility of Mn (Dorman et al., 2001) as well as dose and duration of exposure (Brenneman et al., 2000, Vitarella et al., 2000).

The nasal epithelium has direct synaptic innervation from the trigeminal nerve. Although this projection differs from the olfactory system in both nasal localization and CNS projection, both have direct transganglionic synaptic connections within the CNS. The fact that inhaled metals have been shown to be transported transganglionically (Henriksson et al., 1997; Gianutsos et al., 1997; Tjälve et al., 1996) suggests that the trigeminal system may also provide a direct route of potentially toxicant Mn entry into the CNS. We therefore exposed rats and mice to occupationally relevant levels of $\mathrm{Mn}$ in a nose-only inhalation system and measured the concentration of $\mathrm{Mn}$ in trigeminal ganglia and spinal trigeminal nucleus up to 30 days after exposure using Proton Induced X-ray Emission (PIXE). PIXE is a sensitive method to measure metals in specific anatomical regions without interference from surrounding tissue (Divine et al., 1999). We here present the first evidence of uptake of inhaled Mn within the trigeminal system of rats and mice and its entry into the CNS at acceptable occupational exposure levels. 


\section{METHODS}

\section{Generation of Mn exposure atmosphere}

Many forms of Mn have been shown to enter the CNS following inhalation or intranasal exposures, with deposition dependent on compound solubility (Dorman et al., 2001). Although the exposures reported here used environmentally relevant concentrations, the exposure duration was relatively short compared to lifetime occupational or environmental exposures. Therefore the highly soluble chloride compound (which is more soluble than manganese phosphate) was used to maximize our ability to detect regional deposition with even these relatively short exposures. Previous studies from our group and others have demonstrated that inhaled $\mathrm{MnCl}_{2}$ is successfully transported into the rat brain via the olfactory route (Bench et al., 2001, Brenneman et al., 2000).

The $\mathrm{Mn}$ exposure atmosphere was generated from a $\mathrm{MnCl}_{2}$ solution using a RETEC nebulizer. The exposure atmosphere was characterized for both Mn concentration and particle size distribution. For practical reasons, rats and mice were exposed at two separate occasions. The target particle size of $2 \mu \mathrm{m}$ mass median aerodynamic diameter (MMAD) was chosen to ensure a high nasal olfactory deposition (Cheng et al., 1989). The actual size distribution was $3.1 \pm 1.4 \mu \mathrm{m}$ with a GSD (geometric standard deviation) of $2.29 \pm 0.47 \mu \mathrm{m}$ for rat exposures. Size distribution was $1.98 \pm 0.12 \mu \mathrm{m}$ and GSD $2.3 \pm 0.54$ for mouse exposures. The Mn mean concentration in the exposure atmosphere was $2.3 \pm 1.3 \mathrm{mg} / \mathrm{m}^{3} \mathrm{MnCl}_{2}$ for rats and $2.0 \pm-0.09 \mathrm{mg} / \mathrm{m}^{3}$ $\mathrm{MnCl}_{2}$ for mice and was consistent with an environmentally relevant concentration 
(OSHA 1998). Purity of the exposure atmosphere was verified by Proton Induced X-ray Emission (PIXE, see below), showing no metals other than Mn present.

\section{Animal exposure}

Male and female 9-10 week old Fischer 344/N rats (Charles River Laboratories, Wilmington, MA) and FVB/N mice (Taconic, Germantown, NY) were used as experimental animals. Animals were pre-conditioned for 1-2 hours on 2 consecutive days in the nose-only exposure restraint tubes to minimize the potential stress of a longer exposure. Nose-only exposure was used to minimize systemic accumulation from either skin absorption or from grooming, swallowing and subsequent gastric absorption. All procedures adhered to Institutional Animal Care and Use Committee guidelines at University of New Mexico and Lovelace Respiratory Research Institute.

Rats and mice were exposed to either clean filtered air (vehicle control groups) or 2.0-2.3 mg/m $\mathrm{m}^{3} \mathrm{MnCl}_{2}$ (exposure groups) at a flow rate of $20 \mathrm{~L} / \mathrm{min}$. Total exposure time was 10 days (5 days@6 hrs/day, 2 days rest, 5 days @6 hrs/day simulating occupational exposures). Both the vehicle control and $\mathrm{MnCl}_{2}$ exposures were run concurrently for each species. During exposures, animals were continuously visually monitored for respiration

rate, depth and regularity, and to ensure no animals turned around in their exposure tubes. The exposure system was continuously monitored for temperature, oxygen level and $\mathrm{Mn}$ concentration.

Following the exposures, the animals were returned to their cages and visually monitored intermittently over the next 12 hours post-exposure. No acute exposure effects 
on rodent behavior were observed. During the course of the exposure 7 of the male $\mathrm{Mn}$ exposed FVB/N mice and 3 of the male control mice received bite wounds requiring treatment consisting of daily cleaning with sterile saline and application of nolvasan, a triple antibiotic ointment containing Neomycin, Polymixin B Sulfates, Bacitracin and

Zinc (Bauch and Lomb). Three of the Mn exposed mice and one of the control mice were treated for eight days and the remaining four Mn exposed mice and two control mice were treated for thirteen days. These animals were distributed across the sacrifice groups to reduce any bias from this treatment. Post-mortem analysis showed no difference between antibiotic-treated mice and other mice in the same experimental group with regard to Mn uptake $(\mathrm{p}=0.8)$.

\section{Animal sacrifice and morphological processing}

Five animals per exposed group and 3 animals per control group were euthanized at each of the time-points $2 \mathrm{~h}$ ( 0 day), 7, 14 and 30 days post-exposure. All animals were sacrificed by $\mathrm{CO}_{2}$ inhalation followed by exsanguination and intracardial perfusion with physiological saline. The brain and trigeminal ganglia were removed and immediately quick-frozen in 2-methylbutane cooled in dry ice to $-40^{\circ} \mathrm{C}$. Frozen tissues were stored at $-80^{\circ} \mathrm{C}$ until cryosectioned. Only fresh frozen tissues were used to avoid metal artifacts from trace contaminants in fixatives and solutions.

One hemisphere of each brain was cryosectioned sagittally at $10 \mu \mathrm{m}$ thickness through the spinal trigeminal nucleus (1.3-1.9 mm lateral of midline for mouse and 1.9$3.4 \mathrm{~mm}$ lateral of midline for rat according to Paxinos and Franklin, 1997, and Paxinos and Watson, 1986, respectively). Trigeminal ganglia were cryosectioned at the same 
thickness. Tissue sections were mounted on nylon foils and freeze-dried for PIXE analysis (see below). In addition, adjacent spinal trigeminal nucleus sections were mounted on glass slides and stained with hematoxylin and eosin (H\&E) to visualize general morphology. The area including the caudal, interpolar and oral part of the spinal trigeminal nucleus (Sp5, according to Paxinos and Franklin, 1997 and Paxinos and Watson, 1986) was encircled on digital images of the $\mathrm{H} \& \mathrm{E}$ stained sections in order to facilitate positioning for PIXE analysis (Figure 1). This region was chosen to ensure measurement of trigeminal projections. A malfunction of a $-80^{\circ} \mathrm{C}$ freezer prior to cryosectioning resulted in the loss of 14 day control and 30 day exposed trigeminal rat ganglia as well as 30 day control and exposed spinal trigeminal nucleus rat tissue.

\section{Proton Induced X-ray Emission Analysis for Mn determination}

Spinal trigeminal nucleus and trigeminal ganglia were analyzed for Mn and other metal content using PIXE and Scanning Transmission Ion Microscopy (STIM) at the nuclear microprobe facility within Lawrence Livermore National Laboratory (Roberts et al., 1999). Proton Induced X-ray Emission (PIXE) is an X-ray fluorescence technique that can use focused $\mathrm{MeV}$ energy proton beams to interrogate specimens and has been previously used by this group to study olfactory uptake of inhaled metals (Divine et al., 1999). It provides accurate quantitation, simultaneous multi-element detection and is capable of micron scale spatial resolution whilst maintaining down to $1 \mathrm{mg} / \mathrm{kg}$ elemental sensitivity (Mauthe et al., 1998). PIXE analysis allows for reliable and sensitive (in the range of 1 picogram) measurement of $\mathrm{Mn}$ in specific anatomical regions without interference from surrounding tissue (Bench et al., 2001). 
For PIXE analysis, $\mathrm{x}$-rays were detected with an energy dispersive HpGe detector that subtended a solid angle of $\sim 120$ millisteradian to the specimen. The detector was located at a scattering angle of 135 degrees. Charge was collected in a biased Faraday cup located behind the sample. Trigeminal ganglia and spinal trigeminal nucleus were examined with beam currents of up to $10 \mathrm{nA}$, for doses of up to 15 microcoulombs. X-ray spectra were stored on computer and analyzed off-line. PIXE and STIM data were obtained using incident $3 \mathrm{MeV}$ proton microbeams. Spinal trigeminal nuclei were identified using H\&E stained images of adjacent sections to guide the position of the beam on the associated freeze-dried section using a 40x optical microscope within the microprobe specimen chamber. An absolute encoder-controlled sample stage was used to position the feature of interest in the beam path with a precision of better than $10 \mu \mathrm{m}$. The size of the beam spot was adjusted to enable analysis of features with different areal dimensions. The beam spot size was maximized to interrogate as much of the feature of interest while avoiding interrogation of surrounding material. Beam spot sizes were square or rectangular and varied between $0.1 \times 0.1 \mathrm{~mm}$ and $1 \times 1 \mathrm{~mm}$.

Following PIXE analysis, STIM was used to measure the residual ion energy of the proton beam after traversing the sample (Lefevre et al., 1987; Bench, 1991; Lefevre et al., 1991). For STIM, beam currents were reduced to a few thousand ions per second. The energy of individual ions after traversing the specimen were measured with a retractable charged particle silicon surface barrier detector located approximately $5 \mathrm{~cm}$ directly behind the sample and in front of the Faraday cup. The surface barrier detector was retracted from the path of the beam during PIXE measurements (the million fold higher beam currents used for PIXE rapidly result in catastrophic detector damage). The median 
value of ten thousand residual ion energies was selected to represent the average residual energy of the ion beam after traversing the sample (Lefevre et al., 1987). Incoming protons typically lost $\sim 40 \mathrm{KeV}$ in traversing the freeze-dried tissue sections.

X-ray spectra were analyzed using the computational iterative PIXE spectrum fitting code PIXEF to extract characteristic x-ray peak areas (or yields) for elements of interest (Antolak and Bench, 1994). The incident and residual proton energies were used to convert $\mathrm{x}$-ray yields to element concentrations using PIXEF assuming the composition of the biological material to be $\mathrm{C}_{5} \mathrm{H}_{9} \mathrm{O}_{2} \mathrm{~N}$. This assumption enables one to accurately model the slowing down of the proton beam as it passes through the sample and attenuation of the $\mathrm{x}$-rays as they traverse the sample prior to detection and therefore obtain accurate $\mathrm{mg} / \mathrm{kg}$ elemental concentrations. It has been shown that this assumption accurately models ion energy loss in a whole variety of biologic materials with an accuracy of better than $90 \%$ (Lefevre et al., 1987; Bench, 1991; Lefevre et al., 1991).

To verify the system calibration for Mn quantitation, thin film organic matrix standards containing $\mathrm{Mn}$ at concentrations of 21,80 and $100 \mathrm{mg} / \mathrm{kg}$ were analyzed under the same conditions used for analysis of tissue sections each day tissues were analyzed. Measured Mn contents from both standards were always within $5 \%$ of the known Mn contents. Analysis of the standards also revealed that minimum detection limits for $\mathrm{Mn}$ in an organic matrix under the analysis conditions were $\sim 1 \mathrm{mg} / \mathrm{kg}$.

\section{Statistical analysis}

Mn concentrations were measured in left and right trigeminal ganglia and in spinal 
trigeminal nucleus from one hemisphere of the brain. Within- animal (bilateral) homogeneity of Mn concentrations was assessed graphically and with Spearman's rank correlation analysis before measurements were averaged and analyzed further. Effects of species, gender, exposure, and days post exposure on Mn deposition in trigeminal ganglia and spinal trigeminal nucleus were evaluated using generalized linear model analysis of variance models where variances were modeled as log-linear functions of exposure type (Littell et al. 1996). Heterogeneous variance models were used because we expected that the variance for exposed animals would be greater than for controls. Dunnett's multiple comparisons tests were used to compare least-squares adjusted mean concentrations in exposed animals to pooled controls at different time points. Mn clearance rates from trigeminal ganglia and spinal trigeminal nucleus were estimated by nonlinear regression assuming a first order loss model:

where

$$
C(t)=\bar{C}_{\text {controls }}+\beta_{0} e^{-\lambda t},
$$

- $\mathrm{C}(\mathrm{t})$ is average Mn concentration at $t$ days post exposure with $t$ rounded to integer values $(0,7,1430)$

- $\bar{C}_{\text {controls }}$ is the average concentration in control animals over the study

- $\beta_{0}$ estimates the increase in Mn concentration over controls at 0 days post exposure

- $\lambda$ is the loss rate $\left(\mathrm{d}^{-1}\right)$ of $\mathrm{Mn}$. 


\section{RESULTS}

\section{Manganese Uptake, Deposition and Clearance in Trigeminal Ganglion}

Previous data from inhalation exposures has indicated nasal bilateral asymmetry in toxicant deposition and toxicity, so side-to side comparisons of trigeminal ganglion deposition were evaluated (Lewis et al., 1994). With few exceptions Mn concentrations in rat and mouse trigeminal ganglia was very similar for each side analyzed. There was no consistent difference between sides and the estimated correlation between left and right trigeminal ganglion was 0.77 for rats and 0.88 for mice. However, within-animal variation in trigeminal ganglion for rats (mean standard deviation $=0.72$ ) was greater than for mice (mean standard deviation $=0.29$ ). One female rat in the day 0 group showed apparent unilateral uptake of Mn (right trigeminal ganglion $7.5 \mathrm{mg} / \mathrm{kg}$, left trigeminal ganglion $1.6 \mathrm{mg} / \mathrm{kg}$ ). Because of the bilateral consistency in all but this animal, left and right trigeminal ganglia results for each animal were averaged before additional analyses.

Air exposed control mice did not display trends over time for Mn concentrations $(\mathrm{P}=0.4$, Figure $2 \mathrm{~A})$ and there was no gender-related difference in average $\mathrm{Mn}$ concentrations of controls $(\mathrm{P}=0.7)$. Average control mouse trigeminal ganglion $\mathrm{Mn}$ concentrations were $1.7 \mathrm{mg} / \mathrm{kg}$, $(95 \%$ confidence limits for mean $(\mathrm{CLM})=1.5$ to 1.8 and $95 \%$ confidence limits for an individual prediction $(\mathrm{CLI})=0.9$ to 2.4$)$. Manganese levels in trigeminal ganglion of Mn-exposed mice were highest at 0 days post exposure and gradually declined (Figure 2A), and changes in Mn concentration were not affected by gender (Table 1). When compared to pooled controls, average Mn concentrations in 
exposed mice were significantly elevated at 0,7 , and 14 days post exposure but not at 30 days post exposure (or 90 days post-exposure, not shown). The size of this increase at 0 days was $3.0 \pm 0.4(\mathrm{SE}) \mathrm{mg} \mathrm{Mn} / \mathrm{kg} ; 1.8 \pm 0.3$ at 7 days; and $0.7 \pm 0.2$ at 14 days. Residual variation was about 6 times greater in exposed mice than in controls. The number of exposed mice with trigeminal ganglion Mn concentrations greater than the upper $95 \%$ CLI for the pooled control groups was as follows: day 0 , female $=5 / 5$ and male $=5 / 5 ;$ day 7 , female $=5 / 5$ and male $=4 / 5 ;$ day 14 , female $=2 / 5$ and male $=3 / 5 ;$ day 30 , female $=0 / 5$ and male $=0 / 5$; and day 90 , female $=0 / 5$ and male $=0 / 5$.

Mn concentrations in control rat trigeminal ganglion were similar as in mice and without significant variation due to gender $(\mathrm{P}=0.4)$ or days post exposure $(\mathrm{P}=0.8$, Figure 2B). The average concentration of $\mathrm{Mn}$ in control rat trigeminal ganglion was 1.7 $\mathrm{mg} / \mathrm{kg}(\mathrm{CLM}=1.5$ to 1.9 and $95 \% \mathrm{CLI}=0.8$ to 2.5$)$. Mn concentrations were significantly increased in exposed rats immediately following exposures (0 days) and levels declined over time (Figure 2B, Table 1). Gender did not affect trigeminal ganglion Mn deposition in exposed rats (Table 1) and average Mn concentrations were significantly higher in exposed rats at 0 days $(3.5 \pm 0.2), 7$ days $(1.9 \pm 0.3)$ and at 14 days $(1.2 \pm 0.3)$ post exposure when compared to pooled controls (Figure 2B). Residual variation for exposed rats was about 6 times the variation of control rats. The number of exposed rats with trigeminal ganglion Mn concentrations greater than the upper 95\% CLI for the pooled control rats was as follows: day 0 , female $=5 / 5$ and male $=5 / 5$; day 7 , female $=4 / 5$ and male $=3 / 5$; and day 14 , female $=3 / 5$ and male $=4 / 5$. Due to the loss of rat trigeminal tissue (see Materials section), Mn content in exposed animals was not analyzed after 14 days. 
Clearance model analyses indicated that exposed rats and mice had similarly elevated Mn concentrations in trigeminal ganglion at day $0(ß 0=3.51 \mathrm{mg} / \mathrm{kg}$ and 3.10 $\mathrm{mg} / \mathrm{kg}$ increases, respectively, Table 2$)$ and that clearance rates were similar $\left(0.084 \mathrm{~d}^{-1}\right.$

for rats and $0.094 \mathrm{~d}^{-1}$ for mice). These clearance rates resulted in a $t_{1 / 2}$, mouse of 7.4 days, and $\mathrm{at}_{1 / 2 \text {, rat }}$ of 8.3 days.

In summary, these data demonstrate a significantly elevated concentration of $\mathrm{Mn}$ in both rat and mouse trigeminal ganglia immediately after the 10 day inhalation exposure followed by a gradual decline in trigeminal Mn content to control levels over 30 days.

\section{Manganese Uptake, Deposition and Clearance in Spinal Trigeminal Nucleus}

Concentrations of $\mathrm{Mn}$ in the spinal trigeminal nucleus of air (vehicle)-exposed mice did not display trends over time for $\mathrm{Mn}$ concentrations $(\mathrm{P}=0.2$, Figure $3 \mathrm{~A})$, but there was a small difference between genders $(\mathrm{P}=0.05)$ after adjusting for daily variation in concentrations. Average control mouse spinal trigeminal nucleus concentrations for females were $3.4 \mathrm{mg} / \mathrm{kg}(\mathrm{CL}=3.2$ to 3.6 and $\mathrm{CLI}=2.7$ to 4.1$)$ compared to $3.7 \mathrm{mg} / \mathrm{kg}$ for males $(\mathrm{CL}=3.5$ to 3.9 and $\mathrm{CLI}=3.0$ to 4.4$)$. The average concentration for genders combined was $3.6 \mathrm{mg} / \mathrm{kg}(\mathrm{CL}=3.4$ to 3.7 and $\mathrm{CLI}=2.8$ to 4.2$)$. Because $\mathrm{Mn}$ concentration in mouse spinal trigeminal nucleus was not significantly different for genders ( $\mathrm{P}=0.10$, Table 3$)$, control groups could be pooled for further comparisons. Manganese concentration in spinal trigeminal nucleus from Mn-exposed mice was different from pooled controls at day 7 but not for other days (Figure 3A). The difference between the spinal trigeminal nucleus Mn concentration on day 7 relative to pooled 
controls was $0.6+0.2 \mathrm{mg} \mathrm{Mn} / \mathrm{kg}(\mathrm{P}<0.001)$. Exposed mice were about 2 times as variable as controls. The number of exposed mice with spinal trigeminal nucleus $\mathrm{Mn}$ concentrations over the upper 95\% CLI for the gender-specific control groups were as follows: day 0 , female $=1 / 5$ and male $=0 / 5 ;$ day 7 , female $=3 / 5$ and male $=1 / 5 ;$ day 14 , female $=2 / 5$ and male $=0 / 5$; and day 30 , female $=0 / 5$ and male $=0 / 5$.

As in mice, Mn concentrations in spinal trigeminal nucleus from control rats did not vary significantly with gender or days post exposure. The average control spinal trigeminal nucleus concentration for control females was $3.5 \mathrm{mg} / \mathrm{kg}(\mathrm{CLM}=3.2$ to 3.8 and $\mathrm{CLI}=2.5$ to 4.5$)$ compared to $3.6 \mathrm{mg} / \mathrm{kg}$ for males $(\mathrm{CL}=3.3$ to 3.9 and $\mathrm{CLI}=2.6$ to 4.6) and $3.6 \mathrm{mg} / \mathrm{kg}$ when genders were combined ( $\mathrm{CL}=3.4$ to 3.8 and $\mathrm{CLI}=2.6$ to 4.5$)$.

In contrast to mice, rat spinal trigeminal nucleus Mn concentrations were significantly increased at day 0 and declined over time (Figure 3B). Although analyses indicated that complex gender $\mathrm{x}$ time interactions were statistically significant (Table 3), differences in concentrations were small. At days 0,7 , and 14 the increase in exposed female rats over pooled controls was $0.53 \mathrm{mg} / \mathrm{kg}, 0.54 \mathrm{mg} / \mathrm{kg}$, and $0.23 \mathrm{mg} / \mathrm{kg}$, respectively, compared to $0.82 \mathrm{mg} / \mathrm{kg}, 0.35 \mathrm{mg} / \mathrm{kg}$, and $0.03 \mathrm{mg} / \mathrm{kg}$ for male rats. If genders are pooled, exposed rat spinal trigeminal nuclei contained $0.7 \pm 0.2 \mathrm{mg} / \mathrm{kg}$ more Mn than controls at day $0,0.4 \pm 0.2 \mathrm{mg} / \mathrm{kg}$ more $\mathrm{Mn}$ at day 7 , and $0.1 \pm 0.1 \mathrm{mg} / \mathrm{kg}$ more Mn at day 14.

Exposed rat spinal trigeminal nucleus Mn concentrations were about 5 times as variable as for control rats. The number of exposed rats with spinal trigeminal nucleus Mn concentrations over the upper 95\% CLI for the pooled control groups were as 
follows: day 0 , female $=2 / 5$ and male $=2 / 5 ;$ day 7 , female $=1 / 5$ and male $=0 / 5 ;$ day 14 , female $=0 / 5$ and male $=0 / 5$.

We performed clearance model analyses on spinal trigeminal nucleus results for rats but not for mice, because mouse results did not qualitatively match a first-order loss model. The estimated clearance rate for rats was $0.088 \mathrm{~d}^{-1}(95 \% \mathrm{CL}=-0.010-0.186)$ and the clearance half-time was 7.9 days. Average control rat concentration was 3.5 $\mathrm{mg} / \mathrm{kg}(\mathrm{CL}=3.3-3.7)$ and the increase in Mn concentrations at day 0 in exposed rats was $0.7 \mathrm{mg} / \mathrm{kg}(\mathrm{CL}=0.4-1.0)$.

\section{DISCUSSION}

Data presented here indicate that trigeminal uptake of inhaled metals provides an effective mechanism for direct entry of toxicants into the CNS. Relatively short-term inhalation of $\mathrm{Mn}$ at concentrations relevant for occupational exposure results in deposition of Mn within the trigeminal ganglia, and to a lesser degree also within the spinal trigeminal nucleus. A robust effect is suggested due to similar trends in the data of both rats and mice.

Manganese content in the trigeminal ganglia from exposed animals was approximately 2 -fold higher than in control animals on day 0 ( $2 \mathrm{~h}$ following the 10 -day exposure) and Mn levels declined over time to return to baseline levels at 30 days post 
exposure in mice. Although Mn concentration data were incomplete at 14 days for control rats and 30 days for exposed rats (see Methods section), Mn concentrations and trends in exposed rats were similar to mice. The similar trend for Mn uptake and clearance in mice and rats strongly suggests that Mn levels had also returned to baseline levels at 30 days for rats.

A transsynaptic transport of $\mathrm{Mn}$ has previously been demonstrated in the olfactory system and we therefore investigated whether trigeminal Mn would also enter the CNS via its projection to the spinal trigeminal nucleus. Indeed, there was a small but significant elevation of Mn levels in rat spinal trigeminal nucleus immediately after the Mn exposure and up to 7 days thereafter. The pattern of Mn uptake in spinal trigeminal nucleus from mice was slightly different than for rats, a significant elevation of Mn levels above control values was only seen 7 days post-exposure for mice. Compared to Mn levels in trigeminal ganglion, metal uptake in spinal trigeminal nucleus was relatively low. It is possible that the 0 and 7 day time points did not capture the peak concentration in either species.

Although we had originally hoped to calculate a clearance curve for both species for the trigeminal ganglion as well as the spinal trigeminal nucleus and did calculate clearance for the rat from the spinal nucleus, the uncertainty about capturing the peak concentrations in the spinal trigeminal nucleus in either species raises questions about the relevance of this clearance rate. Further studies at shorter time intervals would be necessary to characterize both deposition and clearance rates for the spinal trigeminal nucleus. For the trigeminal ganglia, however, the deposition and clearance rates, as well 
as the peak concentrations observed are remarkably similar across the two species, suggesting a fairly robust effect.

Evidence is accumulating that inhaled Mn can be directly transported into the brain via the olfactory nerve (as opposed to secondary systemic transport via the lungs). Our group and others have demonstrated that inhalation of Mn leads to substantially higher Mn levels in olfactory bulbs than e.g. liver or kidneys, supporting a direct transport of the metal into the brain (Bench et al., 2001, Normandin et al., 2002). In addition, rats with unilateral nostril occlusion exposed to Mn inhalation showed elevated Mn concentrations in olfactory bulb of the unoccluded side whereas Mn levels were equivalent to air-exposed animals on the occluded side (Brenneman et al., 2000). Although the neuronal architecture of the olfactory and trigeminal systems differ, the fact that both have sensory receptors within the nasal epithelium and project directly to the CNS suggest that similar pathways for toxicant entry may exist. The consistent deposition of Mn observed within the trigeminal ganglia as well as the somewhat lesser deposition in the spinal trigeminal nuclei are consistent with transport to the spinal nucleus through projections from the ganglia. These data support the conclusion that a similar pattern of uptake may occur within the trigeminal system as has been observed in the olfactory system, and that direct trigeminal uptake of $\mathrm{Mn}$ from the nasal cavity is responsible for the increased $\mathrm{Mn}$ deposition in the spinal trigeminal nucleus in our current study.

To our knowledge, no other study has demonstrated trigeminal uptake of metals after inhalation exposure of environmentally relevant doses. A previous study by MollerMadsen et al. (1992) investigated the distribution of mercury in brain after inhalation 
exposure of mercury vapor, which differs in uptake dynamics from mercury metal. In Moller-Madsen's study, mercury was found in several brain regions, including the mesencephalic nucleus of the trigeminal nerve, at an exposure of $500 \mu \mathrm{g} / \mathrm{m}^{3}$ for $4-8 \mathrm{~h}$. However, at the threshold limit value of $50 \mu \mathrm{g} / \mathrm{m}^{3}$ for $8 \mathrm{~h}$, mercury was found only in vessel walls and not in trigeminal nucleus or other brain regions.

Several investigators, including our group, have previously focused on the olfactory route as a mechanism for deposition of inhaled metals into the CNS in concentrations greater than those found with systemic distribution and without penetrating the blood-brain-barrier. The possibility that a similar route of entry can occur via the trigeminal pathways posses additional questions concerning the possibility of a direct role of inhaled toxicants in neurodegenerative disease. Although the intranasal chemosensory trigeminal system does not appear to be affected by the neuronal degeneration seen in Parkinson's disease (Barz et al. 1997), a link between substantia nigra pars reticulata and spinal nucleus of the trigeminus controlling the blink reflex has been suggested (Basso et al. 1996). Hyperexcitability reflex blink is frequently seen in patients with Parkinson's disease. It is also worth noting that trigeminal motor neurons are affected in a subset of cases with Amyotrophic Lateral Sclerosis (ALS) (e.g. DePaul et al. 1988), a neurodegenerative disease primarily linked to degeneration of spinal motor neurons. Although about $20 \%$ of ALS cases are familial, the cause for the remaining $80 \%$ is not established, but environmental factors have been implicated (McGuire et al. 1997, Kamel et al.2002). In addition, trigeminal motor neurons contain a lower degree of calcium-chelating protein parvalbumin than cranial neurons not affected in ALS (e.g. oculomotor and trochlear neurons) (Reiner et al. 1995), raising the possibility that 
trigeminal Mn uptake could lead to severe long-term effects because of an impaired resistance to excitotoxic and oxidative stress in trigeminal motor neurons. Whether chronic exposure of environmentally relevant doses of Mn causes clinical and pathological features similar to those seen in neurodegenerative disorders remains to be established. Therefore, potential for direct toxicant entry to the CNS via the trigeminal route suggests a new avenue for research in the development of neurodegenerative disease. 


\section{ACKNOWLEDGEMENTS}

This work was supported by NIEHS RO1-ES10766, NIEHS P20 ES09871-03, and

NIEHS P30 ES-012072. This work was performed in part under the auspices of the U.S.

Department of Energy by University of California, Lawrence Livermore National

Laboratory under Contract No. W-7405-Eng-48. 


\section{REFERENCES}

Antolak AJ, Bench G. PIXEF: The Livermore PIXE Spectrum Analysis Package. Nucl. Inst and Meth In Phys Res 1994;B90:596-601

Barz S, Hummel T, Pauli E, Majer M, Lang CJ, Kobal G. Chemosensory event-related potentials in response to trigeminal and olfactory stimulation in idiopathic Parkinson's disease. Neurology 1997;49:1424-31

Basso MA, Evinger C. An explanation for reflex blink hyperexcitability in Parkinson's disease. II. Nucleus raphe magnus. J Neurosci 1996;16:7318-30

Bench, G. Scanning Transmission Ion microscopy. Ph. D. Thesis. University of Melbourne, Melbourne, Australia; 1991.

Bench G, Carlsen TM, Grant PG, Wollett JS Jr, Martinelli RE, Lewis JL, Divine KK. Olfactory bulb uptake and determination of biotransfer factors in the California ground squirrel (Spermophilus beecheyi) exposed to manganese and cadmium in environmental habitats. Environ Sci Technol. 2001;35:270-7. 
Brenneman KA, Wong BA, Buccellato MA, Costa ER, Gross EA, Dorman, DC. Direct Olfactory Transport of Inhaled Manganese ((54) $\mathrm{MnCl}(2))$ to the Rat Brain: Toxicokinetic Investigations in a Unilateral Nasal Occlusion Model. Toxicol. Appl. Pharmacol. 2000;169: $238-48$

Cheng YS, Barr EB, Yeh HC. A Venturi Disperser as a Dry Powder Generator for Inhalation Studies. Inhal Toxicol 1989;1:365-71

DePaul R, Abbs JH, Caligiuri M, Gracco VL, Brooks BR. Hypoglossal, trigeminal, and facial motoneuron involvement in amyotrophic lateral sclerosis. Neurology 1988;38:2813

Divine KK, Grant PG, Lewis JL, Bench G. Quantitative Particle Induced X-Ray Emission Imaging of Rat Olfactory Epithelium Applied to the permeability of Rat Epithelium to Inhaled Aluminum Chem Res Toxicol 1999;12:575-81

Dorman DC, Struve MF, James RA, Marshall MW, Parkinson CU, Wong BA. Influence of particle solubility on the delivery of inhaled manganese to the rat brain: manganese sulfate and manganese tetroxide pharmacokinetics following repeated (14-day) exposure. Toxicol Appl Pharmacol. 2001;170:79-87 
Gianutsos G, Morrow GR, Morris JB. Accumulation of Manganese in Rat Brain following Intranasal Administration. Fundam Appl Toxicol 1997;37:102-5

Henriksson J, Tallkvist J, Tjälve H. Uptake of Nickel into the Brain via Olfactory Neurons in Rats. Toxicol Lett 1997;91:153-62

Henriksson J, Tallkvist J, Tjälve H. Transport of manganese via the olfactory pathway in rats: dosage dependency of the uptake and subcellular distribution of the metal in the olfactory epithelium and the brain. Toxicol Appl Pharmacol. 1999;156:119-28.

Kamel F, Umbach DM, Munsat TL, Shefner JM, Hu H, Sandler DP. Lead exposure and amyotrophic lateral sclerosis. Epidemiology 2002;13:311-9

Kaiser J. Manganese: a high-octane dispute. Science. 2003;300:926-8

Lefevre HW, Schofield RMS, Overley JC, McDonald JC. Scanning Transmission Ion Microscopy as it complements Particle Induced X-ray Emission microscopy. Scan Micr 1987;1:879-89 
Lefevre HW, Schofield RMS, Bench G, Legge GJF. STIM with Energy Loss Contrast: An Imaging Modality Unique to MeV Ions. Nucl Instr and Meth In Phys Res 1991;B54:363-70

Lewis JL. Hahn FF, Dahl AR. Transport of Inhaled Toxicants to the Central Nervous System - Characteristics of a Nose-Brain Barrier. In: The Vulnerable Brain and Environmental Risks, Volume 3: Toxins in Air and Water, Isaacson RL, Jensen KF., editors. New York: Plenum Press, 1994. p 77-103

Littell, RC, Milliken, GA, Stroup, WW, and Wolfinger, RO. SAS system for mixed models. SAS Institute, Cary, NC. 1996.

Mauthe RJ, Sideras-Haddad E, Turteltaub KW, and Bench G. Quantitative Imaging Microscopy for the Sensitive Detection of Administered Metal Containing Drugs in single cells and tissue slices-A demonstration using Platinum based chemotherapeutic Agents. J. Pharm Biomed Anal 1998;17:651-63

McGuire V, Longstreth WT Jr, Nelson LM, Koepsell TD, Checkoway H, Morgan MS, van Belle G. Occupational exposures and amyotrophic lateral sclerosis. A populationbased case-control study. Am J Epidemiol 1997;145:1076-88 
Moller-Madsen, B. Localization of mercury in CNS of the rat. V. Inhalation exposure to metallic mercury. Arch Toxicol 1992;66:79-89

Normandin L, Panisset M, Zayed J. Manganese neurotoxicity: behavioral, pathological, and biochemical effects following various routes of exposure. Rev Environ Health. $2002 ; 17: 189-217$

Occupational Safety and Health Administration (OSHA). Occupational Safety and Health Standards, Toxic and Hazardous Substances. Code of Federal Regulations 29 CFR 1910.1000. 1998.

Paxinos, G. and Watson, C. The rat brain in stereotaxic coordinates. $2^{\text {nd }}$ edition. Orlando: Academic Press, 1986

Paxinos, G. and Franklin KBJ. The mouse brain in stereotaxic coordinates. $2^{\text {nd }}$ edition San Diego: Academic Press, 1997,

Reiner A, Medina L, Figueredo-Cardenas G, Anfinson S. Brainstem motoneuron pools that are selectively resistant in amyotrophic lateral sclerosis are preferentially enriched in parvalbumin: evidence from monkey brainstem for a calcium-mediated mechanism in sporadic ALS. Exp Neurol 1995;131:239-50 
Ressler T. Wong J, Roos J. Manganese speciaion in exhaust particulates of automobiles using MMT-containing gasoline. J Synchrotron Radiation 1999;6:656-8

Roberts ML, Grant PG, Bench GS, Brown TA, Franz BR, Morse DH, Antolak AJ. The Stand-Alone Microprobe at Livermore. Nucl Instr and Meth In Phys Res 1999;B158:2430

Tjälve H, Henriksson J, Tallkvist J, Larsson BS, Lindquist NG. Uptake of Manganese and Cadmium from the Nasal Mucosa into the Central Nervous System via Olfactory Pathways in Rats. Pharmacol Toxicol 1996;79:347-56

Tjälve H, Henriksson J. Uptake of Metals in the Brain via Olfactory Pathways. Neuro Toxicol 1999;20:181-96

Vitarella D, Wong BA, Moss OR, Dorman DC. Pharmacokinetics of inhaled manganese phosphate in male Sprague-Dawley rats following subacute (14-day) exposure. Toxicol Appl Pharmacol. 2000;163:279-85 
Table 1. Analysis of variance summary of factors affecting Mn deposition in mouse and rat trigeminal ganglion.

\begin{tabular}{|c|c|c|c|c|c|}
\hline Species & Source & Numerator $\mathrm{df}$ & Denominator $\mathrm{df}$ & F-value & $\mathrm{P}$ - value \\
\hline \multirow[t]{8}{*}{ Mouse } & Exposure & 1 & 58 & 75.18 & $<0.001 * * *$ \\
\hline & Day & 4 & 58 & 26.22 & $<0.001 * * *$ \\
\hline & Exposure x Day & 4 & 58 & 17.64 & $<0.001 * * *$ \\
\hline & Gender & 1 & 58 & 0.16 & 0.69 \\
\hline & Exposure x Gender & 1 & 58 & 0.45 & 0.50 \\
\hline & Gender x Day & 4 & 58 & 0.14 & 0.97 \\
\hline & Exposure x Gender & 4 & 58 & 0.76 & 0.56 \\
\hline & x Day & & & & \\
\hline \multirow[t]{8}{*}{ Rat } & Exposure & 1 & 35 & 147.19 & $<0.001 * * *$ \\
\hline & Day & 3 & 35 & 13.12 & $<0.001 * * *$ \\
\hline & Exposure x Day & 1 & 35 & 10.4 & $0.003 * *$ \\
\hline & Gender & 1 & 35 & 0.44 & 0.51 \\
\hline & Exposure x Gender & 1 & 35 & 0.00 & 0.98 \\
\hline & Gender x Day & 3 & 35 & 0.12 & 0.95 \\
\hline & Exposure x Gender & 1 & 35 & 0.02 & 0.89 \\
\hline & x Day & & & & \\
\hline
\end{tabular}

** $\mathrm{P}<0.01, * * * \mathrm{P}<0.001$ 
Table 2. Parameter estimates $(95 \% \mathrm{CL})$ for predicting clearance rate $(\lambda)$ and half-time $\left(\mathrm{t}_{1 / 2}\right)$ of $\mathrm{Mn}$ from mouse and rat trigeminal ganglion, $C(t)=\bar{C}_{\text {controls }}+\beta_{0} e^{-\lambda \text { days }}$

\begin{tabular}{lllll} 
Species & $\bar{C}_{\text {controls }}(\mathrm{mg} / \mathrm{kg})$ & $\beta_{0}(\mathrm{mg} / \mathrm{kg})$ & $\lambda(1 / \mathrm{d})$ & $\mathrm{t}_{1 / 2}(\mathrm{~d})$ \\
\hline Mouse & $1.62(1.41-1.84)$ & $3.10(2.63-3.57)$ & $0.094(0.061-0.127)$ & $7.4(5.5-11.4)$ \\
Rat & $1.67(1.30-2.04)$ & $3.51(2.92-4.11)$ & $0.084(0.050-0.116)$ & $8.3(6.0-13.9)$ \\
\hline
\end{tabular}


Table 3. Analysis of variance summary of factors affecting Mn deposition in mouse and rat spinal trigeminal nucleus.

\begin{tabular}{llllll}
\hline Species & Source & Numerator $\mathrm{df}$ & Denominator df & F-value & P - value \\
\hline Mouse & Exposure & 1 & 48 & 1.96 & 0.17 \\
& Day & 3 & 48 & 5.17 & $0.004 * *$ \\
Exposure x Day & 3 & 48 & 2.83 & 0.05 \\
Gender & 1 & 48 & 1.01 & 0.32 \\
Exposure x Gender & 1 & 48 & 2.8 & 0.10 \\
Gender x Day & 3 & 48 & 1.23 & 0.31 \\
Exposure x Gender x Day & 3 & 48 & 0.65 & 0.58 \\
Rat & & & & \\
Exposure & 1 & 35 & 19.29 & $<0.001 * * *$ \\
Day & 2 & 35 & 1.24 & 0.30 \\
Exposure x Day & 2 & 35 & 5.41 & $0.009 * *$ \\
Gender & 1 & 35 & 0.87 & 0.36 \\
Exposure x Gender & 1 & 35 & 1.64 & 0.21 \\
Gender x Day & 2 & 35 & 6.28 & $<0.001 * * *$ \\
Exposure x Gender x Day & 2 & & 2.06 & 0.15 \\
\hline
\end{tabular}

** $\mathrm{P}<0.01, * * * \mathrm{P}<0.001$ 


\section{FIGURE LEGENDS}

Figure 1. Sagittal section from rat brain stained with Hematoxylin and Eosin to visualize general morphology in order to localize the spinal nucleus ("SP", encircled area).

Figure 2. Mn concentrations in mouse and rat trigeminal ganglia0-30 days after 10 days inhalation exposure to $\mathrm{MnCl}_{2}$. For both mice (A) and rats (B), Mn levels were significantly elevated in trigeminal ganglion immediately after Mn exposure and levels gradually declined over time. Error bars are \pm one standard error of the mean, and asterisks denote results from one-sided Dunnett's tests that exposed animals have higher concentrations than pooled control animals $(* * \mathrm{P}<0.01$, *** $\mathrm{P}<0.001)$.

Figure 3. Mn concentrations in mouse and rat spinal trigeminal nucleus 0-30 days after 10 days inhalation exposure to $\mathrm{MnCl}_{2}$. There was a small but significant elevation of $\mathrm{Mn}$ levels in mouse spinal trigeminal nucleus at 7 days post-exposure (A) and in rat spinal trigeminal nucleus 0 and 7 days post-exposure (B). Error bars are \pm one standard error of the mean, and asterisks denote results from one-sided Dunnett's tests that exposed animals have higher concentrations than pooled control animals $\left(* \mathrm{P}<0.05,{ }^{* *} \mathrm{P}<0.01\right.$, $* * * \mathrm{P}<0.001)$. 
Fig 1

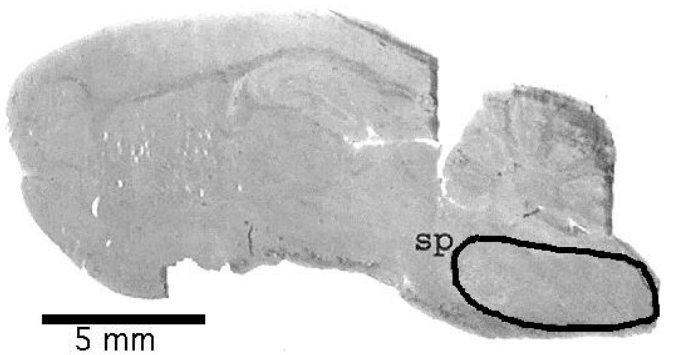


Fig 2
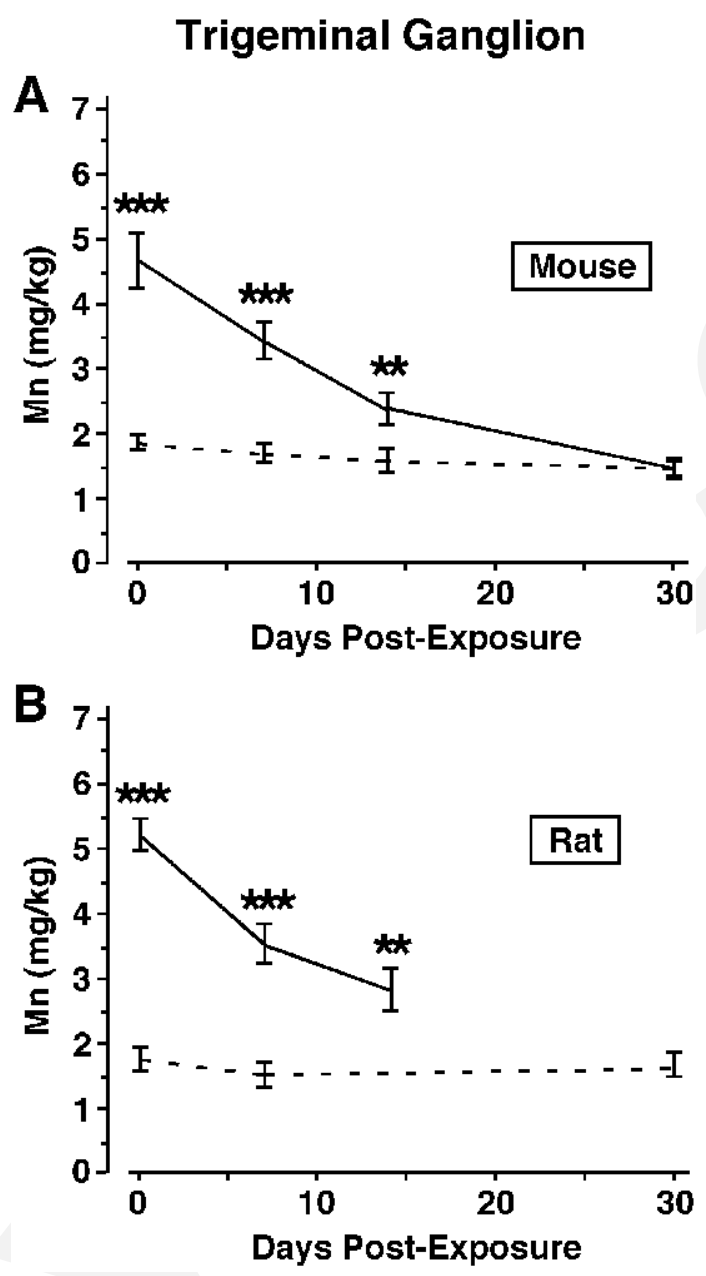
Fig 3

Spinal Trigeminal Nucleus
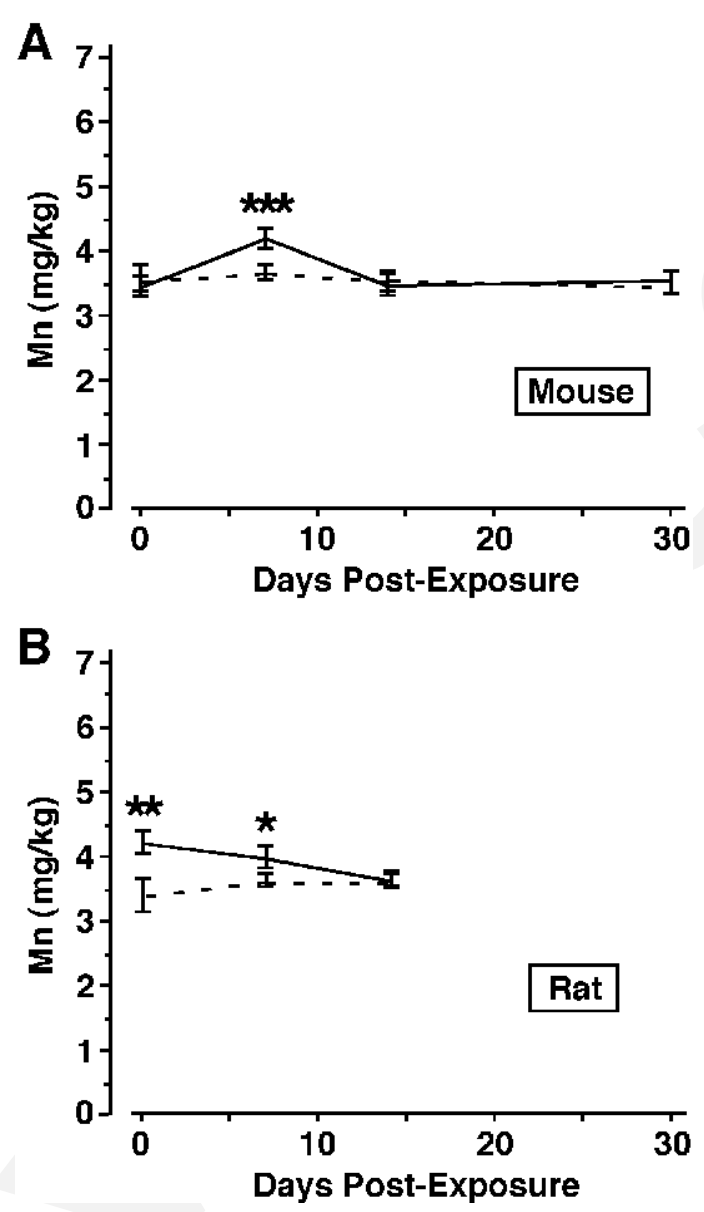